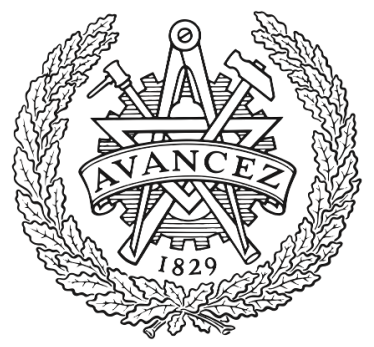

CHALMERS

UNIVERSITY OF TECHNOLOGY

\title{
Bed material as a catalyst for char gasification: The case of ash-coated olivine activated by $K$ and $S$ addition
}

Downloaded from: https://research.chalmers.se, 2023-04-26 06:06 UTC

Citation for the original published paper (version of record):

Berdugo Vilches, T., Maric, J., Knutsson, P. et al (2018). Bed material as a catalyst for char gasification: The case of ash-coated olivine activated by $\mathrm{K}$ and S addition. Fuel, 224: 85-93. http://dx.doi.org/10.1016/j.fuel.2018.03.079

N.B. When citing this work, cite the original published paper. 


\title{
Bed material as a catalyst for char gasification: the case of ash-coated olivine activated by $\mathrm{K}$ and $\mathrm{S}$ addition
}

Teresa Berdugo Vilches*, Jelena Maric, Pavleta Knutsson, Daniel C. Rosenfeld, Henrik

Thunman, Martin Seemann

Department of Space, Earth and Environment (SEE), Division of Energy Technology, Chalmers University of Technology, 41296 Göteborg, Sweden

*Corresponding author: berdugo@chalmers.se

\begin{abstract}
In this paper, the ability of an ash-coated olivine to catalyze the steam gasification of biomassderived char is investigated in a laboratory reactor. The olivine investigated is a sample from the Chalmers dual fluidized bed gasifier and it has been activated by the in-bed addition of $S$ and $\mathrm{K}_{2} \mathrm{CO}_{3}$. The char and bed material samples were analyzed by Scanning Electron Microscopy coupled with Energy Dispersive X-ray Spectroscopy (SEM-EDS). It is shown that the ash layer coating of the olivine can catalyze the steam gasification of char by transferring catalytic potassium (K) to the char particles. The mobilities of the catalytic species from the olivine ash-layer are discussed. This work furthers the current understanding of the catalytic activities of ash-coated bed material particles during the thermochemical conversion of carbonaceous feedstocks in fluidized beds. In addition, it complements the existing literature on catalytic bed materials, which to date have focused on tar removal and improving gas quality.
\end{abstract}

Keywords: char, olivine, potassium, sulfur, catalytic gasification, ash-layer, fluidized bed

\section{Introduction}

The steam gasification of char is a chemical reaction that is relevant for a number of thermochemical processes, such as gasification and chemical looping combustion (CLC). The 
reactivity of char towards steam depends on its morphological structure, as well as on its content of catalytic inorganic matter [1]. The artificial addition of catalytic inorganic matter to carbonaceous feedstocks has been widely investigated as a strategy for accelerating the relatively slow kinetics of the gasification reaction. In this context, various catalysts, ranging from transition metals (e.g. Fe, Ni, Co, Cu) to Alkali and Alkaline Earth Metals (AAEM), have been investigated [2]. Wet impregnation and mechanical mixing of the char and catalyst are the most commonly used contact methods [1].

In fluidized bed gasifiers, the catalyst is usually introduced in the form of a bed material rather than being premixed with the fuel; the main goal being to improve the gas quality by, for example, reducing the amount of tar. Accordingly, there is an extensive body of literature on in situ tar reduction $[3,4]$, whereas the influence of the bed material on char gasification has been largely overlooked. As pointed out by Nzihou et al. [2], catalytic char gasification is usually masked by the catalytic effects of the bed materials towards tar reactions.

Investigations that have focused on the interactions between the bed material and char have shown that the gasification rate can be enhanced indirectly by the bed material. For instance, lower inhibition of the char gasification reaction by, e.g., $\mathrm{H}_{2}$ and tar species, can be attained when the bed materials influence the concentrations of inhibiting species around the char particle [5]. In a previous study that examined the use of various bed materials in the Chalmers gasifier [6], the correlation between the concentrations of inhibiting gases and char conversion was found to be weak, leading to the suspicion that there is an additional catalytic activity of the bed material towards the char gasification reaction.

Keller et al. [7] have demonstrate the possibility for a bed material to catalyze the char gasification reaction by transferring potassium $(\mathrm{K})$ from the bed material to the char particle. Their investigation was carried out in the context of CLC and used a manganese ore that was pre-soaked in $\mathrm{K}_{2} \mathrm{CO}_{3}$. After the bed material was soaked, the $\mathrm{K}$ was uniformly distributed over 
the cross-section of the manganese particles, and the bed material became a source of catalytic $\mathrm{K}$ for the char gasification reaction during the subsequent CLC experiment.

In the case of fluidized bed gasification, the catalytic activity of naturally occurring bed materials, such as olivine, has been attributed to an external layer that is rich in catalytic ash elements [8, 9]. It is generally accepted that ash-coated olivine can effectively lower the tar content of the product gas, as well as catalyze the water-gas shift (WGS) equilibrium [6, 10, 11]. However, the interactions that occur between the ash-layer and the char have not been explored previously.

The aim of this work was to provide conclusive evidence that the active ash-layer in olivine can catalyze the steam gasification reaction, and that this catalysis occurs by a process similar to that described by Keller et al. [7]. For this purpose, steam gasification experiments were carried out in a laboratory reactor with untreated and ash-coated olivine, respectively. Char and bed material samples were examined to elucidate the mobility of catalytic species from the bed material to the char in a gasification environment.

\section{Theoretical background}

Char reactivity. In the present work, char reactivity is characterized as the overall reactivity $\left(\mathrm{R}_{\mathrm{m}}\right)$, which is normalized to the initial mass of char, and it is defined according to Eqs. (1) and (2)

$$
R_{m}(t)=-\frac{1}{m_{o}} \frac{d m_{c}(t)}{d t}
$$

where $m_{o}$ is the initial mass char, $m_{c}(t)$ is the remaining unconverted char, and $X_{c}(t)$ is the degree of char conversion at time $t$.

$$
X_{c}(t)=\frac{m_{o}-m_{c}(t)}{m_{o}}
$$


For a given fuel, the reactivity of the char is strongly influenced by the char preparation method [12-14], e.g., the heating rate [13-15], cooling step after devolatilization [16], and devolatilization temperature $[15,17]$, as this determines the porosity $[13,14]$ and alkali content $[15,17]$ of the produced char. Therefore, the quantification of reactivity is here applicable only for comparisons of experimental cases. For dedicated kinetic investigations relevant to fluidized bed gasification (i.e., in-bed pyrolysis), the reader is referred to other studies [18] for different types of biomasses, and to the study of Lundberg et al. [19] for the reactivity of large wood particles.

Using a fluidized bed of non-catalytic silica sand, Lundberg and colleagues found that the reactivity $\left(R_{m}\right)$ curves of centimeter-sized wood pellets peaked at a conversion rate of around $5 \%$, which was followed by a steady decrease of the gasification rate [16]. Similar curves were observed by Ahmed and coworkers for the steam gasification of woodchips in a drop tube reactor [20]. For large char particles, the gasification rate is typically dominated by the mass transfer at the beginning of the conversion [16, 19]; and the shape of the reactivity curve is influenced by the development of the reactive surface and that of the ash content, as conversion proceeds [13].

When there is artificial addition of AAEM catalysts to the char, a direct correlation between the catalyst load and the reactivity of the char is commonly observed [21-23]. For a similar catalyst load, K-catalysts have higher catalytic activity than Ca-based catalysts [23-25]. The reactivity curves $\left(\mathrm{R}_{\mathrm{m}}\right)$ exhibit different shapes, e.g., a wide maximum [21], a maximum in the late conversion range [22], or even a sustained gasification rate [26]. Zhang et al. [24] have described the different locations of the maximum as a function of the concentration of active AAEM elements in the char. Furthermore, Lobo [26] proposed that the achievement of a steady gasification rate over wide ranges of conversion rates can be explained by the action of a stable catalytic front. 
Active ash layer in olivine. Olivine is a magnesium-iron silicate material that can contains some impurities, such as $\mathrm{Ni}$ and $\mathrm{Cr}$. In a combustion/gasification environment with ashcontaining fuels, the untreated olivine particles become coated with ash-forming elements. The morphological features of an already developed layer are typically: (1) an inner layer that is homogeneous and melt-like type; followed by (2) a more heterogeneous outer layer [27]. The inner layer may comprise two zones: an innermost Ca-rich region surrounded by a Mg-rich region, which is thought to be formed as $\mathrm{Mg}$ ions are expelled from the olivine structure when Ca ions are incorporated into the structure [28]. The composition of the outermost layer is closer to that of the fly ash [27].

In dual fluidized bed (DFB) gasifiers, where the bed material circulates between a combustor and a steam gasifier, ash-coated olivine transports inorganic species between the reactors, by means of the ash layer. The transport of $\mathrm{K}$ from the combustor to the gasifier has been confirmed by Kirnbauer et al. [29], who investigated the flows of inorganic matter in the Güssing gasification plant. Apart from the transport of K, Marinkovic et al. [8] have demonstrated the transport of sulfur from the combustor to the gasifier, which in the Chalmers gasifier results in a higher concentration of $\mathrm{H}_{2} \mathrm{~S}$ in the raw gas than can possibly be ascribed to the fuel. Marinkovic et al. [8] describe that $\mathrm{S}$ acts as a carrier of reactive $\mathrm{K}$, by promoting the formation of $\mathrm{K}_{2} \mathrm{SO}_{4}$, which is transported by the ash-coated olivine particles. In line with the formation of a Ca-rich layer and the transport of $\mathrm{K}$, the catalytic properties of the ash-coated olivine have been attributed to both the Ca-rich layer itself [9], as well as to the mobile K transported by the material [8].

Catalyst mobility. The superior catalytic activity of K (over Ca) has been ascribed in part to its higher mobility. For instance, K can move in gaseous form, whereas Ca typically moves in the form of solid particles [30]. In fact, the chemical deactivation of K-catalysts occurs when K reacts with $\mathrm{Si} / \mathrm{Al}$ to form non-volatile silicates or aluminosilicates [31]. Ca has been found to 
prevent the chemical deactivation of $\mathrm{K}$ by preventing its reaction with $\mathrm{Si} / \mathrm{Al}$, thereby ensuring that $\mathrm{K}$ is available in a mobile form [32, 33].

Early studies conducted by Hüttinger and Minges [34] point to $\mathrm{KOH}$ as a key catalyst precursor, and attribute the catalytic activities of other K-salts to their prior conversion to $\mathrm{KOH}$. In this way, $\mathrm{K}_{2} \mathrm{SO}_{4}$ may enter the catalytic scheme via the reduction to $\mathrm{K}_{2} \mathrm{~S}$, as proposed previously by the same group [35]. The release of $\mathrm{KOH}(\mathrm{g})$ can also occur from the Ca-K-Si and Ca-K-P systems, and this process is enhanced in a steam environment [36]. This was attributed to the promoted decomposition of $\mathrm{K}_{2} \mathrm{CO}_{3}$ into $\mathrm{KOH}(\mathrm{g})$. The release of $\mathrm{KOH}(\mathrm{g})$ from the $\mathrm{K}-\mathrm{Al}-\mathrm{Si}$ system has also been proposed by Keller and coworkers to explain the transfer of $\mathrm{K}$ from the $\mathrm{Mn}$ ore to the char particles [7]. Some of the sources of releasable potassium in a steam gasification environment are listed in Table 1.

Table 1. Potential sources of gas-phase K, relevant to the steam gasification environment.

\begin{tabular}{ll} 
& Ref \\
\hline $\mathrm{K}_{2} \mathrm{CO}_{3}$ & {$[21,37]$} \\
$\mathrm{K}_{2} \mathrm{SO}_{4}, \mathrm{~K}_{2} \mathrm{~S}$ & {$[8,35]$} \\
System Ca-K-Si & {$[36]$} \\
System Ca-K-P & {$[36]$} \\
System K-Al-Si & {$[7]$} \\
\hline
\end{tabular}

\section{Experimental}

The experimental matrix was designed to examine the catalytic activity of the ash layer of the olivine, as well as to investigate the mobility of the catalytic species from the olivine to the char particles. As a reference case, a char gasification experiment was carried out in a bed of untreated olivine (Oliv), which did not possess an ash layer. The catalytic activity of ash-coated olivine was tested in three consecutive gasification tests using the same batch of ash-coated olivine: AshOliv; AshOliv-Run2; and AshOliv-Run3. This allowed testing of the stability and decay of the catalytic activity of olivine during prolonged exposure to a steam gasification environment. 
Furthermore, partially gasified char particles, i.e., $\mathrm{X}_{\mathrm{c}}=40 \%$, were produced in a bed of untreated (Oliv-40\%) or ash-coated olivine (AshOliv-40\%), respectively, for further analysis. The codes for the experimental cases and the solid samples (char and bed material) that were collected at the end of each gasification test are summarized in Table 2.

Table 2. Summary of experiments. Samples collected at the end of each char gasification test are marked as $(x) . X_{c}$ refers to the char conversion degree in each experiment.

\begin{tabular}{lllll}
\hline $\begin{array}{l}\text { Experiment } \\
\text { code }\end{array}$ & Bed material tested & $\begin{array}{l}\mathbf{X}_{\mathbf{c}} \\
\mathbf{( \% )}\end{array}$ & $\begin{array}{l}\text { Char } \\
\text { sample }\end{array}$ & $\begin{array}{l}\text { Bed } \\
\text { sample }\end{array}$ \\
\hline Oliv-40\% & Untreated olivine & 40 & $\mathrm{x}$ & \\
Oliv & Untreated olivine & 100 & & \\
AshOliv-40\% & Ash-coated olivine & 40 & $\mathrm{x}$ & $\mathrm{x}$ \\
AshOliv & Ash-coated olivine & 100 & & \\
AshOliv-Run2 & Ash-coated olivine after case AshOliv & 100 & & $\mathrm{x}$ \\
AshOliv-Run3 & Ash-coated olivine after case AshOliv-Run 2 & 100 & & \\
\hline
\end{tabular}

Char preparation method. The char particles tested were produced by devolatilization of wood pellets (5-mm diameter) in $\mathrm{N}_{2}$ in a thermogravimetric analyzer (TGA). The heating program consisted of a drying step at a heating rate of $16^{\circ} \mathrm{C} /$ min increasing from $25^{\circ} \mathrm{C}$ to $130^{\circ} \mathrm{C}$, followed by a devolatilization step at a heating rate of $49^{\circ} \mathrm{C} / \mathrm{min}$, and reaching a maximum temperature of $915^{\circ} \mathrm{C}$. The end-temperature was chosen so that the char was free of volatiles at the temperature of the subsequent gasification tests. After holding the char samples at $915^{\circ} \mathrm{C}$ for $7 \mathrm{~min}$, the char was cooled down and pieces of similar size and of a length suitable for the fuel feeding system were selected (i.e., 10-mm length). The elemental analyses of the wood pellets and the ash fraction are presented in Tables 3-4, respectively.

Table 3. Elemental analysis of the wood pellets.

\begin{tabular}{ll}
\hline Element & wt\%, dry basis \\
\hline C & 50.3 \\
H & 6.1 \\
O & 43.1 \\
N & 0.07 \\
S & $<0.01$ \\
Cl & $<0.01$ \\
Ash & 0.4 \\
\hline
\end{tabular}


Table 4. Elemental composition of the ash fraction of the wood pellets.

\begin{tabular}{ll}
\hline Ash element & $\begin{array}{l}\text { Ash content } \\
\text { (mg/kg dry fuel) }\end{array}$ \\
\hline $\mathrm{Al}$ & 36.6 \\
$\mathrm{Si}$ & 149.2 \\
$\mathrm{Fe}$ & 35.6 \\
$\mathrm{Ti}$ & 2.0 \\
$\mathrm{Mn}$ & 107.5 \\
$\mathrm{Mg}$ & 147.3 \\
$\mathrm{Ca}$ & 866.2 \\
$\mathrm{Ba}$ & 12.0 \\
$\mathrm{Na}$ & 35.0 \\
$\mathrm{~K}$ & 387.3 \\
$\mathrm{P}$ & 56.8 \\
\hline
\end{tabular}

Olivine material. The olivine material used in this work was olivine sand of Norwegian origin, provided by Sibelco Nordic. The untreated olivine was a batch of olivine sand as received, with the composition shown in Table 5. The ash-coated olivine comprised olivine of the same origin as the untreated olivine, which had been used in the Chalmers dual fluidized bed (DFB) system [38] and activated with the help of additives (i.e., $\mathrm{S}$ and $\mathrm{K}_{2} \mathrm{CO}_{3}$ ) during the gasification operation, as described previously [6]. The ash-coated olivine was sampled $24 \mathrm{~h}$ after the additives were introduced. The sampling position was at the loop seal that leads the bed material into the gasifier, and therefore the olivine sample is representative of the material that enters the gasifier side of the DFB. The bed sample was taken with a custom-made probe-tube equipped with a water-cooled circuit, and connections for pressurized air and suction lines. The probe was cleaned with pressurized air prior sampling. At the sampling port, pressurized $\mathrm{N}_{2}$ was applied to clear the path from particles during insertion and retrieval of the probe into and out of the loop seal. Once the probe was inserted, suction was applied for a few seconds to extract the bed sample, typically 300-500g. The material remained in the probe during a few minutes to cool down before it was collected.

Table 5. Composition of the untreated olivine material, as provided by the supplier. 


\begin{tabular}{ll}
\hline $\mathrm{MgO}$ & 49.6 \\
$\mathrm{SiO}_{2}$ & 41.7 \\
$\mathrm{Fe}_{2} \mathrm{O}_{3}$ & 7.4 \\
$\mathrm{Al}_{2} \mathrm{O}_{3}$ & 0.46 \\
$\mathrm{Cr}_{2} \mathrm{O}_{3}$ & 0.31 \\
$\mathrm{NiO}$ & 0.32 \\
\hline
\end{tabular}

Experimental setup. The gasification tests were carried out in a laboratory-scale reactor constructed of stainless steel, with an inner diameter of $48 \mathrm{~mm}$ and height of $425 \mathrm{~mm}$. The reactor is hosted in an electrically heated oven. A schematic of the experimental setup is provided in Fig. 1. The char particles are dropped by gravity from the top of the reactor, and the bed material is fluidized with a mixture of steam in $\mathrm{N}_{2}$. The steam is produced in a controlled evaporator-mixer equipped with a liquid-flow-controller (LFC). The $\mathrm{N}_{2}$ is required to ensure the stability of the steam flow, and it is supplied by a mass-flow-controller (MFC). Downstream of the reactor, the product gas is cooled to condense the steam, and the dry gas flow and its composition are thereafter analyzed online using the NGA 2000 MLT gas analyzer (Emerson Process Management GmbH, Baar, Switzerland). The species assayed are: $\mathrm{CH}_{4}, \mathrm{CO}, \mathrm{CO}_{2}$, and $\mathrm{H}_{2}$.

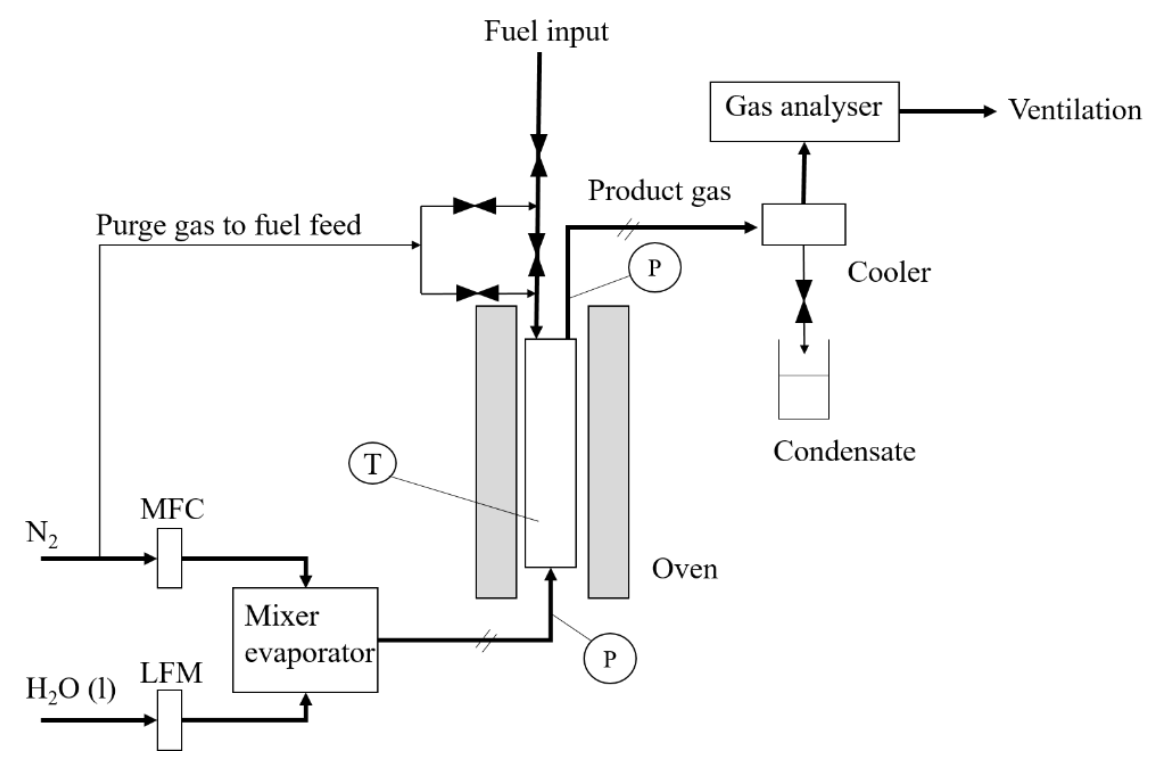


Figure 1. Schematic of the experimental setup applied in the char gasification experiments.

Experimental procedure. A batch of $15 \mathrm{~g}$ of bed material was introduced into the reactor and heated to $900^{\circ} \mathrm{C}$ in $\mathrm{N}_{2}(500 \mathrm{~mL} / \mathrm{min})$. A flow of $400 \mathrm{~mL} / \mathrm{min}$ of steam was then applied, i.e., $44.4 \% \mathrm{vol}$ steam in $\mathrm{N}_{2}$. When the steam flow was stable, i.e., after 3-4min, $0.4 \mathrm{~g}$ of char was fed to the reactor together with a pulse of $\mathrm{N}_{2}$ (to prevent air from entering the reactor). The gasification test proceeded as long as carbon-containing gases were detected by the analyzer, or alternatively, the test was interrupted at $X_{c}=40 \%$ when the aim was to produce a sample of partially gasified char. To end the experiment, the steam flow was stopped, and the reactor was cooled in an atmosphere of $\mathrm{N}_{2}$. The bed sample and, when applicable, the remaining char were retrieved from the reactor at room temperature.

For each batch, the overall reaction rate $\left(R_{m}\right)$ and the degree of carbon conversion $\left(X_{c}\right)$ are derived from the time-resolved composition of the product gas, according to Eqs. (1-4).

$$
m_{c}(t)=m_{o}-\frac{P \cdot M_{c}}{R \cdot T} \int_{0}^{t} \dot{V}_{\text {dry gas }}(t) \cdot\left(X_{C O}(t)+X_{C_{2}}(t)+X_{C_{4}}(t)\right) d t \quad \text { Equation (3) }
$$

where $X_{i}(t)$ refers to the concentration of the carbon-containing gases in the dry gas. The total flow of dry gas $\dot{V}_{\text {dry gas }}(t)$ is determined using $\mathrm{N}_{2}$ as a tracer, as the flow of $\mathrm{N}_{2}$ to the reactor $\left(\dot{V}_{N_{2}}(t)\right)$ is pre-set and known at all times.

$$
\dot{V}_{\text {dry gas }}(t)=\frac{\dot{V}_{N_{2}}(t)}{\left(1-X_{C O}(t)+X_{C_{2}}(t)+X_{C_{4}}(t)\right)}
$$

The closure of the carbon balance is in the range of $84 \%-93 \%$, and the loss of carbon is mainly due to the entrainment of attrited char particles. For this reason, the calculation of $X_{c}$ is normalized to the total (accumulated) amount of carbon measured after a full conversion experiment. 
Char and bed material analyses. The char and olivine samples were analyzed by Scanning Electron Microscopy coupled with Energy Dispersive X-ray Spectroscopy (SEM-EDS). A Table-top Phenom ProX and Quanta 200FEG equipped with an Oxford EDS were the systems of choice for the evaluations.

Two char samples were analyzed: the Oliv- $40 \%$ and AshOliv-40\% cases. The char samples were cut into slices and fixed on a carbon tape. SEM images and spot analysis were applied to identify changes in morphology and mineral constituents that might influence the reactivity. To allow for comparisons, the two char samples were purposely produced at the same conversion degree, as the concentration of mineral matter and the morphology of the char were expected to change over the period of conversion.

Three bed material samples, which differed with regard to the time they were exposed to the steam/char environment, were selected for analysis: the ash-coated olivine before the laboratory test; the ash-coated olivine collected after the AshOliv40\% case; and the ash-coated olivine collected after the AshOliv-Run3 case. The bed material samples were mounted in epoxy and ground to a flat cross-section. Line-scans were used to investigate the chemical composition of the ash layer and the mobilities of the catalytic species upon exposure to the steam/char environment.

\section{Results and discussion}

Char reactivity. Figure 2 shows examples of the time-resolved dry gas compositions obtained during the steam gasification tests with untreated (Oliv case) and ash-coated (AshOliv case) olivine, respectively. The observed low concentration of $\mathrm{CH}_{4}$ supports the notion that the method used for char preparation fully devolatilizes the wood pellets, such that the main reaction that takes place is the steam gasification of char. The higher molar fraction of $\mathrm{H}_{2}$ and higher $\mathrm{CO}_{2}$ :CO ratio noted for the AshOliv case is in line with the catalysis of the WGS reaction 
and accords with the previous experiences with ash-coated olivine [6, 10, 11]. The concentration of $\mathrm{H}_{2}$ at the end of the gasification test (in Fig.2b) is probably an artifact, as this phenomenon is not observed in other tests conducted with ash-coated olivine.

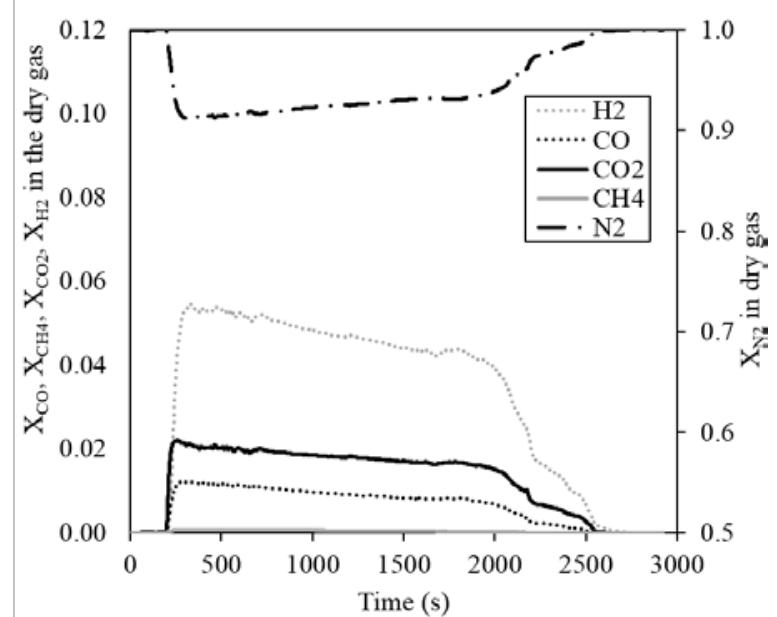

a)

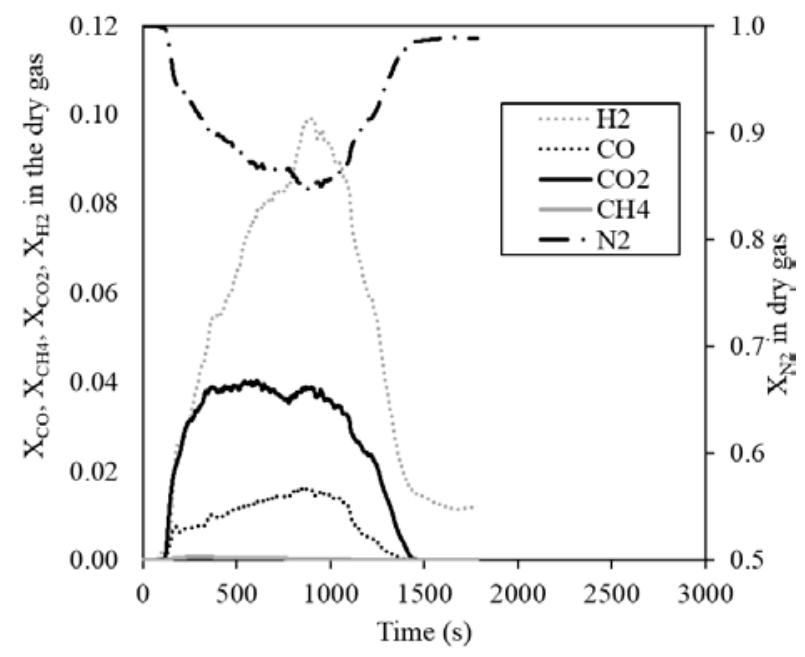

b)

Figure 2. Dry gas compositions over time during gasification experiments in the laboratory fluidized bed reactor. Bed temperature of $900^{\circ} \mathrm{C}, 44.4 \%$ steam in $\mathrm{N}_{2}$. Char particles of 5-mm diameter and 10-mm length, which were prepared by heating wood pellets in TGA to $915^{\circ} \mathrm{C} C$ in $N_{2}$ atmosphere. Bed material: a) Untreated olivine (Oliv); b) Ash-coated olivine (AshOliv).

The reactivity curves for the complete gasification tests are summarized in Fig. 3, for the cases of Oliv, AshOliv, AshOliv-Run2, and AshOliv-Run3. The larger uncertainty in the measurement occurs during the early conversion phase $\left(X_{c}<10 \%\right)$, which can be attributed to the uneven feeding of the char batch. The larger uncertainty in the late conversion phase $\left(X_{c}>80 \%\right)$ is probably due to the enhanced attrition and breakdown of the char into smaller particles during the later stages of the conversion process. Under the tested conditions, mass transfer appears to dominate the early conversion range, i.e., up to $10 \%-15 \%$ conversion, which results in very similar reactivity $\left(\mathrm{R}_{\mathrm{m}}\right)$ values in this range for all the tests. The discussion is, therefore, focused on the differences in reactivity noted within the range where the kinetics determines the conversion and the uncertainty of the measurement is lower, i.e., $X_{c}=10 \%-80 \%$. 


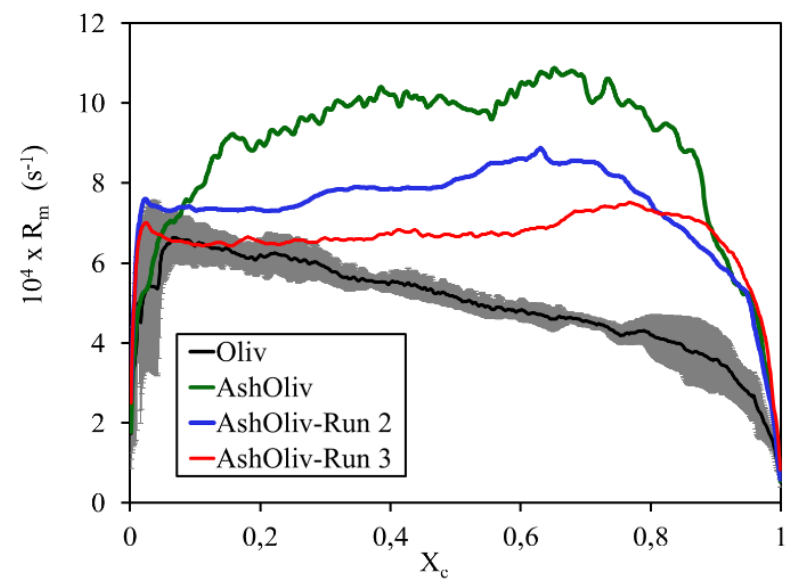

Figure 3. Reactivity curves $\left(R_{m}\right)$ with uncertainty regions (when available) as a function of the degree of char conversion $\left(X_{c}\right)$. Shown are the results for untreated olivine (Oliv) and three consecutive runs using the same batch of ashcoated olivine (Ash-Oliv, Ash-Oliv-Run 2, AshOliv-Run 3). The bed temperature was $900^{\circ} \mathrm{C}$, and fluidization was with $44 \%$ steam in $N_{2}$. Char particles of 5-mm diameter and 10-mm length, prepared by heating wood pellets in TGA, were used.

The major difference between the reactivities of the char gasified in the untreated and ashcoated olivine is the shape of the reactivity curves $\left(R_{m}\right.$ vs $\left.t\right)$, as shown in Fig.3. A maximum at $5 \%$ conversion is observed with untreated olivine, whereas the gasification rate is sustained with a slight increasing tendency in all the cases with ash-coated olivine. The curves derived using untreated olivine have similar shapes to those reported for large char particles in a noncatalytic bed $[16,19]$, and the values of $R_{m}$ are in the same range as those obtained by Mermoud et al. [13], who used a similar char preparation method. With ash-coated olivine, the shape of the reactivity curve is in line with previous observations for catalyst-loaded char [26]. The overall reaction rate is approximately 2-fold (at $X_{c}=50 \%$ ) higher than that quantified in the case of untreated olivine. The catalytic activity of ash-coated olivine towards char gasification is confirmed, despite the concentrations of inhibiting gases, e.g., $\mathrm{H}_{2}$, being higher and continuously increasing, as shown in Fig.2b.

The SEM images of the partially gasified char support the attribution of the higher reactivity in the AshOliv case to the presence of a higher concentration of inorganic matter. In Fig.4, spots rich in mineral matter (mainly Ca and $\mathrm{K}$ ) are visibly more abundant in the char that was gasified 
in a bed of ash-coated olivine. Significant differences in the physical structure (morphology) are not discernible with the SEM and for the magnifications investigated, i.e., magnifications up to 5000×, as evidenced by Figs.4-5.

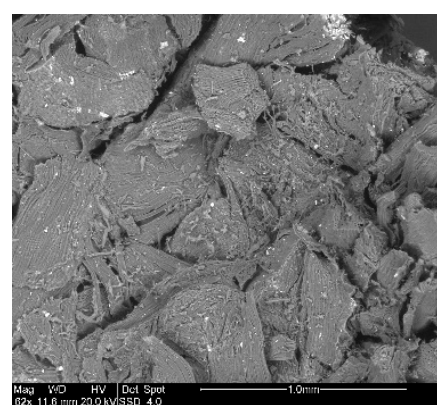

a)

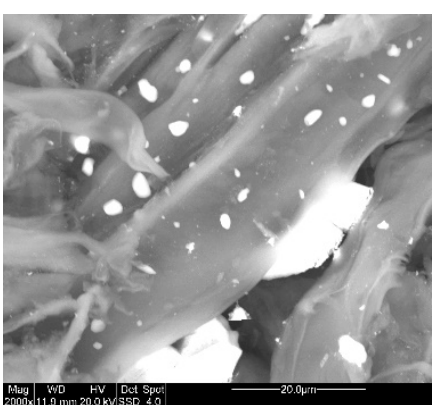

b)

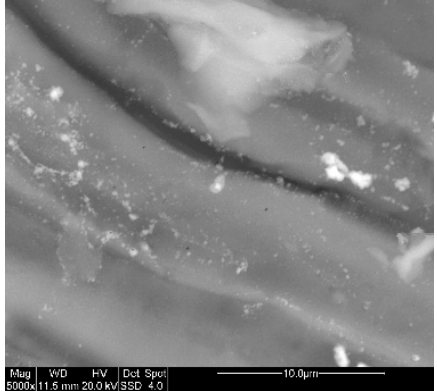

c)

Figure 4. SEM images of the surface features of wood char (40\% conversion) that was gasified at $900^{\circ} \mathrm{C}$ with $44.4 \%$ steam in $N_{2}$ in a fluidized bed of ash-coated olivine: a) overview of the crosssection; b) micron-size particles; c) sub-micron-size particles.

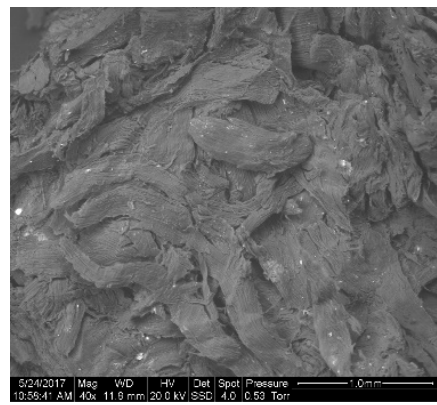

a)

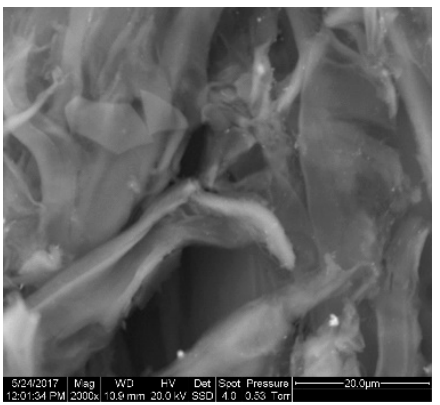

b)

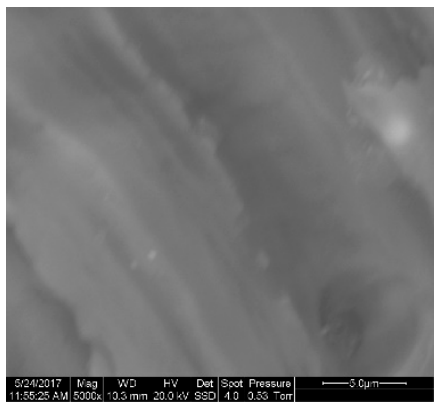

c)

Figure 5. SEM images of the surface features of wood char (40\% converted) that was gasified at $900^{\circ} \mathrm{C}$ with $44.4 \%$ steam in $N_{2}$ in a fluidized bed of untreated olivine: a) overview of the crosssection; b) surface detail at $2000 \times$ magnification; c) surface detail at 5000 $\times$ magnification.

Figure 6 summarizes the line-scan analysis of the cross-section of the char samples, extending from the core of the partially gasified pellet to its external surface. In the AshOliv- $40 \%$ case, clear increases in the concentrations of $\mathrm{Ca}, \mathrm{S}$ and $\mathrm{K}$ are observed towards the external surface. S is detected only in the AshOliv-40\% case, as expected from the activation method used for the bed material. $\mathrm{K}$ is present at concentrations above the detection limits of the instrument (1\%wt.), mainly in the AsOliv-40\% case, whereas Ca is found locally at high concentrations in both samples. 


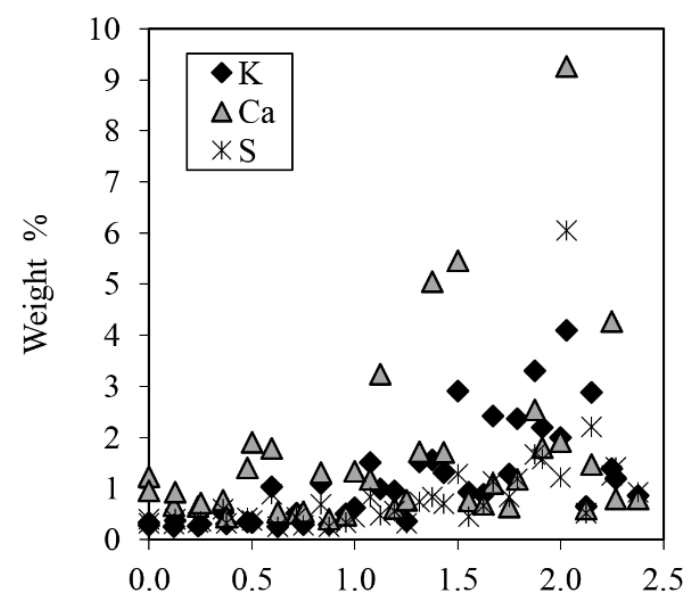

Distance to the center of the char pellet $(\mathrm{mm})$

a)

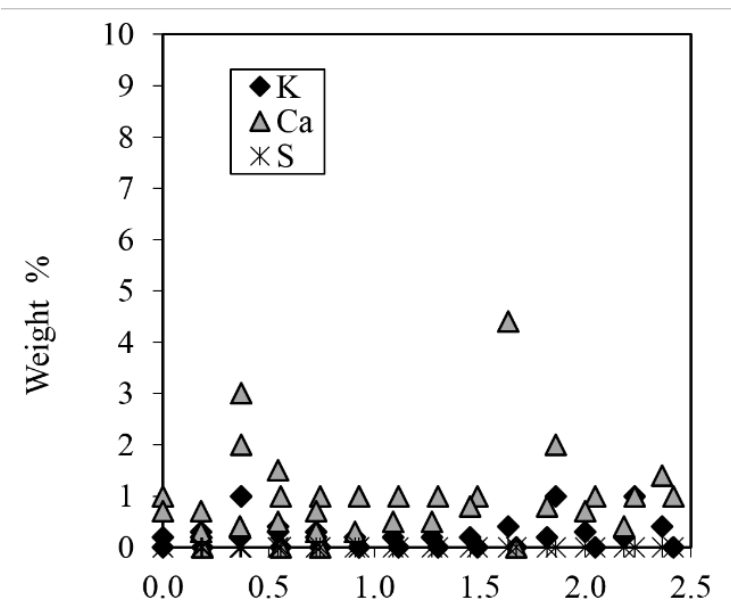

Distance to the center of the char pellet $(\mathrm{mm})$

b)

Figure 6. Concentration profiles of $\mathrm{K}, \mathrm{Ca}$, and $\mathrm{S}$ across the cross-section of a wood char pellet, as analyzed by EDS. Center of the char pellet is at $0 \mathrm{~mm}$. The char pellets were $40 \%$ converted in $44.4 \%$ seam in $\mathrm{N}_{2}$ at $900^{\circ} \mathrm{C}$ in a bed of: a) ash-coated olivine (case AshOliv-40\%). b) Untreated olivine (case Oliv-40\%). Each figure contains two line-scans analyzed in two different slices of the char pellets, respectively.

The concentration profiles of $\mathrm{Ca}$ and $\mathrm{K}$ in Fig.6a should be interpreted with caution, as they could be the results of two phenomena: (1) transport of Ca and K species from the olivine to the char followed by slow dispersion into the char pellet; or/and (2) a profile of carbon conversion, where the gasification reaction is promoted by the adsorbed catalyst, leaving the remainder of mineral matter in a more concentrated form in the areas where carbon has been converted. Regardless of the origin of the mineral matter, it is noteworthy that the concentration profile is flatter in the Oliv- $40 \%$ case. This confirms that the mineral matter profile in the case of ash-coated olivine is created directly and/or indirectly by the external supply of catalyst to the char by the bed material.

Active ash layer in olivine. The investigated olivine particles exhibited a well-developed ash layer, including inner and outer layers. In agreement with a previous study [28], the inner layer showed enrichment of Ca, to the detriment of Mg. In the EDS analysis, the outer layer was found to be rich in the original elements of olivine (Mg, Si, Fe) and in $\mathrm{Ca}$, which presumably originated from the fuel ash [28]. K was commonly found in the outer layer. Figures 7-9 show examples of typical line-scan analyses of the ash-layer of olivine particles with increasing 
exposure to the steam/char environment: AshOliv (before the laboratory test); AshOliv-40\%

( 15 min of exposure); and AshOliv-Run 3 ( $\sim 2$ h of exposure). The focus of the discussion is

on $\mathrm{K}, \mathrm{S}$, and $\mathrm{Ca}$, as these are the species that are found at higher concentrations in char particles gasified in a bed of ash-coated olivine.

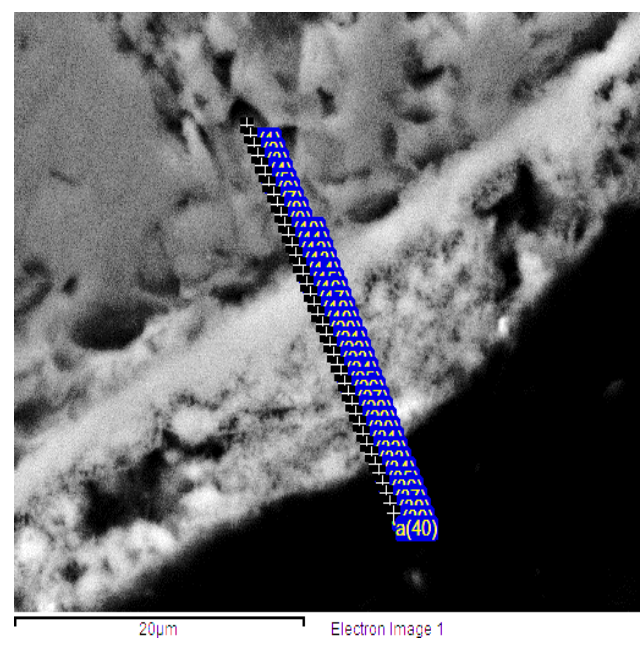

a)

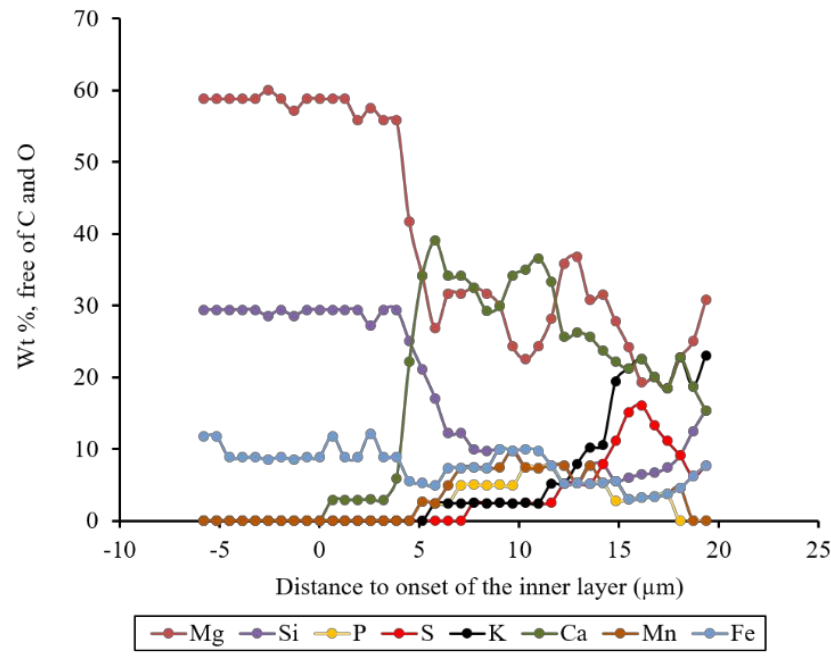

b)

Figure 7. Olivine particle before the laboratory test, i.e. as sampled from the Chalmers gasifier. The particle is Norwegian olivine activated by the in-bed addition of $\mathrm{S}$ and $\mathrm{K}_{2} \mathrm{CO}_{3}$ during operation with woody biomass: a) SEM image of the cross-section of the particle; b) EDS analysis of a line-scan. The onset of the inner layer is arbitrarily defined as the point at which the concentration differs from that of the bulk of the particle.

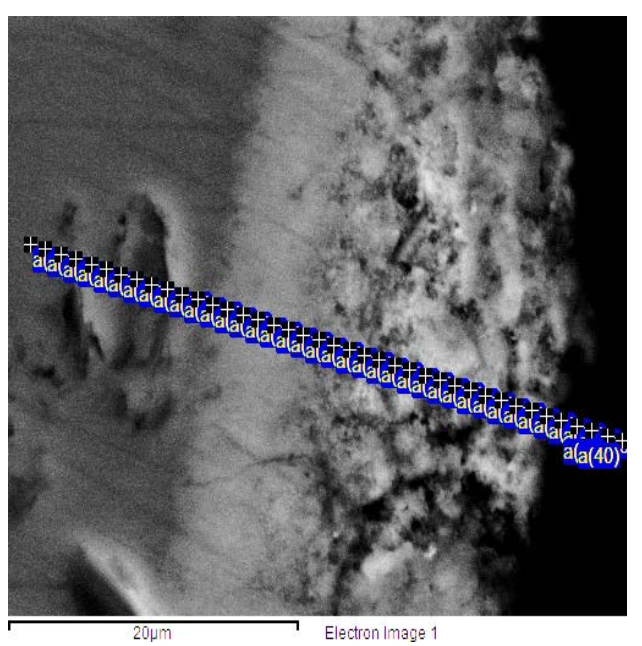

a)

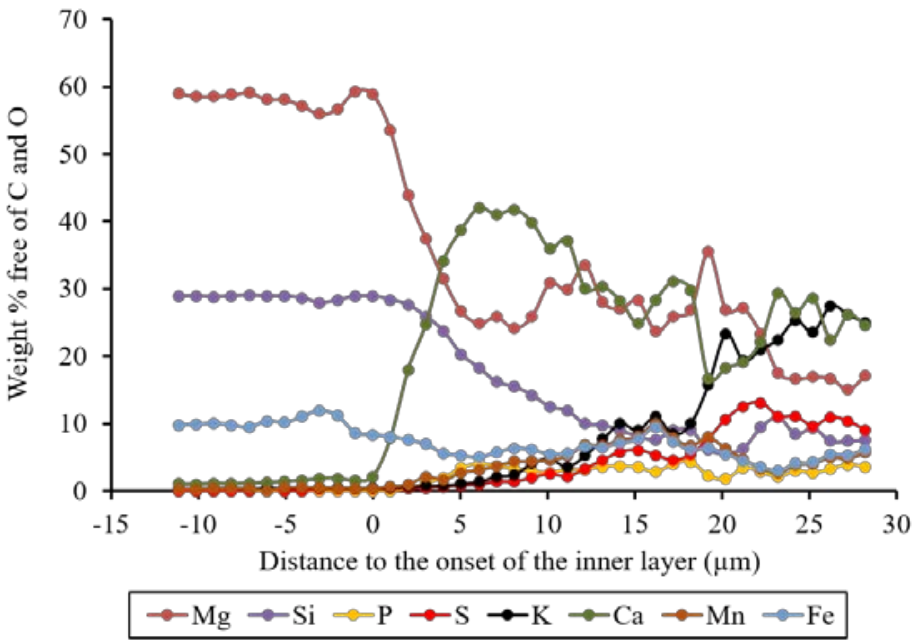

b)

Figure 8. Ash-coated olivine after steam gasification at $900^{\circ} \mathrm{C}$ in the laboratory reactor, i.e., the AshOliv-40\% case: a) SEM image; b) EDS analysis of a line-scan. The onset of the inner layer is arbitrarily defined as the point at which the concentration differs from that of the bulk of the particle. 


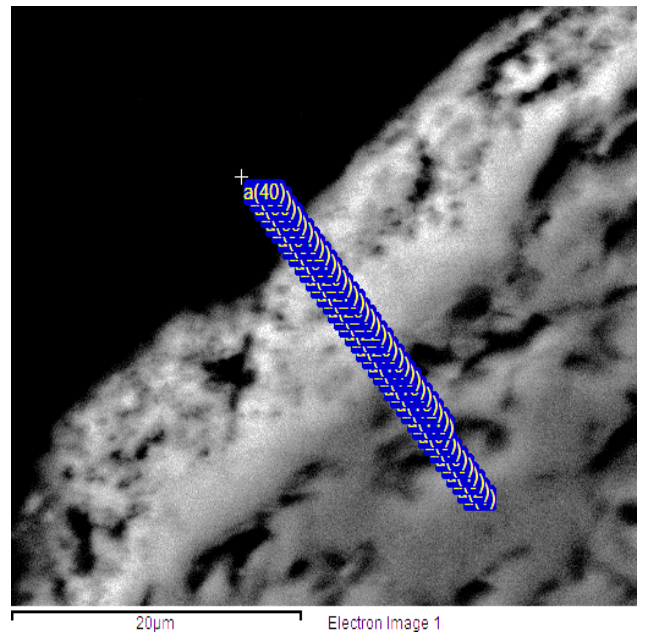

a)

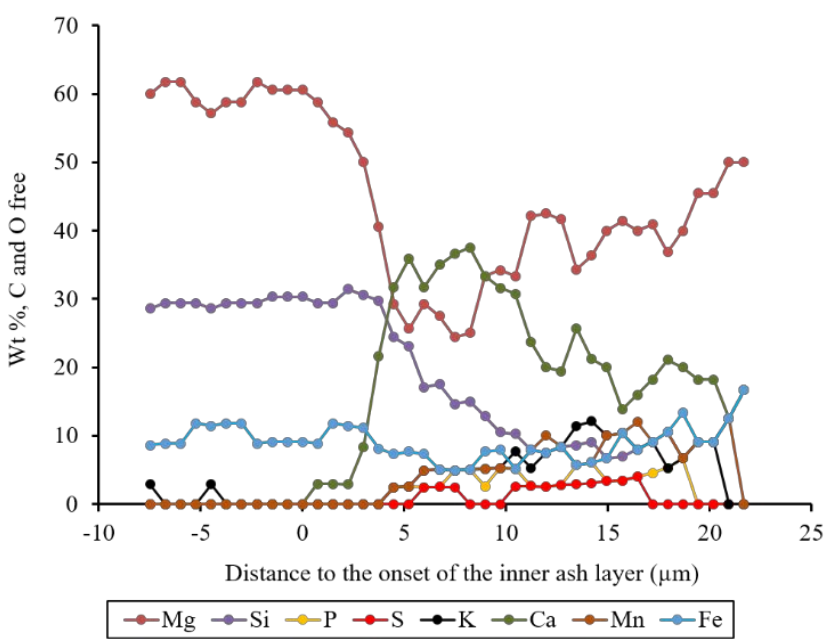

b)

Figure 9. Ash-coated olivine after three consecutive steam gasification tests in a laboratory reactor at $900^{\circ} \mathrm{C}$, i.e., the AshOliv-Run3 case: a) SEM image; b) EDS analysis of a line-scan. Onset of the inner layer arbitrarily defined as the point in which the concentration differs from that of the bulk of the particle

The line-scan of the olivine sample before the laboratory test (Fig.7) and that of the olivine sample after a shorter exposure to steam/char (AshOliv-40\%; Fig.8) are very similar, whereas major differences are noticeable after the olivine was exposed to the steam/char environment for a longer period (AshOliv-Run 3; Fig.9). This indicates that the chemical composition of the ash-coated olivine undergoes a slow transformation, which is in line with the slow decline in catalytic activity of the ash-coated olivine after each consecutive test (cf. Fig.3). Notably, the gasification rate decreases by $18 \%-12 \%\left(\mathrm{R}_{\mathrm{m}, 50 \%}\right)$ relative to the previous run, and after more than $2 \mathrm{~h}$ of exposure to the char/steam environment (the AshOliv-Run 3 case), the ash-coated olivine still catalyzes the char gasification reaction. During the time-window of $1-2 \mathrm{~h}$ of operation, the major chemical changes to the olivine particles seem to occur in the outermost layer, while the composition of the inner molten-alike layer remains stable. Therefore, it is confirmed that the outermost ash layer of ash-coated olivine contributes to the catalytic activity towards steam gasification of char.

Mobility of the catalyst. After a longer period of exposure to the char/steam environment (Fig.9), the bed material contains lower concentrations of S and $\mathrm{K}$ in the outermost layer, which 
is consistent with the corresponding increased levels of $\mathrm{S}$ and $\mathrm{K}$ in the char samples. The Krich area in the outer layer of ash is also enriched with S, which suggests that these two elements are present in combination, e.g., as $\mathrm{K}_{2} \mathrm{~S}$ or $\mathrm{K}_{2} \mathrm{SO}_{4}$, which are potential sources of releasable $\mathrm{K}$ $[7,8]$. We conclude that the profile of $\mathrm{S}$ and, and to some extent that of $\mathrm{K}$, in the char particles gasified in a bed of ash-coated olivine (Fig.6a) can be attributed to the external supply of S and $\mathrm{K}$ by the bed material.

In addition, the outer ash-layer exhibited a decrease in Ca concentration, to the detriment of $\mathrm{Mg}$, after a longer exposure to steam. As the mobility of Ca occurs preferentially in the form of solid particles [30], the possibility for olivine to transport Ca-rich particles was investigated by SEM-EDS, and the results are shown in Fig.10. On the olivine surface, there are particles that are richer in Ca than those found elsewhere on the external surface of the ash-layer, having a composition of approximately 34\% Mg, 39\% Ca, and 11\% Si (wt.\% C- and O-free basis). These Ca-rich particles may account for the apparent enrichment of the ash layer with Mg (Fig.9), although they do not explain the higher concentration of Ca detected in the char gasified in a bed of ash-coated olivine, as Mg was not found at detectable concentrations in the char particles. Therefore, the Ca profile observed in the char particle (Fig.6) is most likely the indirect result of a carbon conversion profile, in which the gasification reaction is promoted in those areas that are accessible to the catalytic K. In conclusion, the locally higher concentration of Ca in the char gasified in ash-coated olivine may contribute to the catalytic char gasification, yet there are not sufficient evidences that this Ca originates from the ash-coat of olivine. 


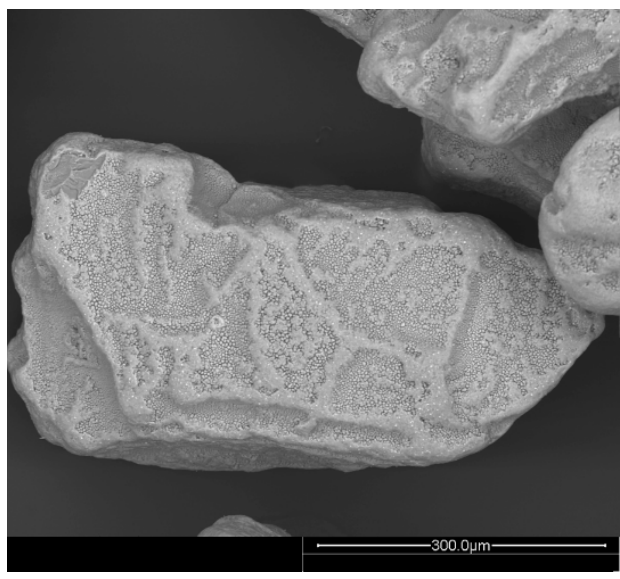

a)

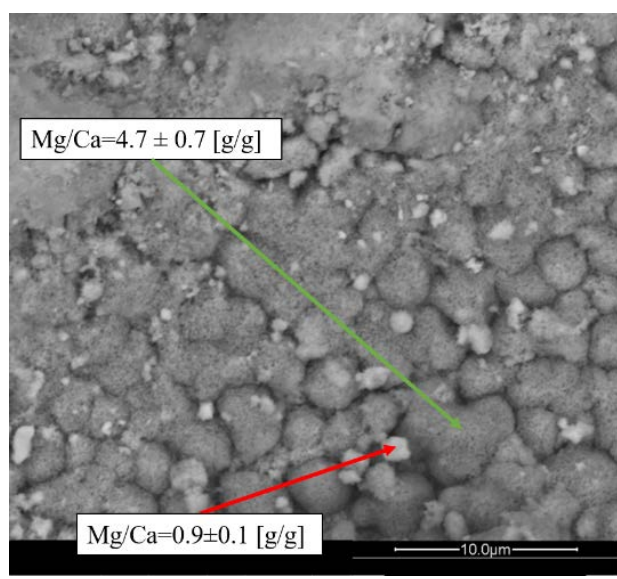

b)

Figure 10. Ash-coated Norwegian olivine as retrieved from the Chalmers gasifier. a) Overview of a particle; b) surface detail with typical Mg-richer areas and Ca-richer particles.

General discussion. The results presented here support the idea that ash-coated olivine catalyzes the steam gasification reaction by a mechanism that is similar to that previously presented by Keller et al. [7] in the context of CLC, whereby K-containing phases within the bed material release $\mathrm{KOH}(\mathrm{g})$ in the presence of $\mathrm{H}_{2} \mathrm{O}$. An important difference between their investigation and the present work is that they showed that the $\mathrm{K}$ was located in the bed material in $\mathrm{Si} / \mathrm{Al} / \mathrm{K}$-rich phases, whereas in the present work we show that the $\mathrm{K}$ is located in S-rich locations. Therefore, a plausible route for the release of $\mathrm{K}$ in this work involves the reaction of $\mathrm{K}_{2} \mathrm{~S}$ with steam, which could contribute to the release of gaseous $\mathrm{KOH}$ and $\mathrm{H}_{2} \mathrm{~S}$ in contact with $\mathrm{H}_{2} \mathrm{O}$, as proposed previously [35]. This type of $\mathrm{K}$ release pathway is also consistent with the unusually high $\mathrm{H}_{2} \mathrm{~S}$ concentration measured in the raw gas produced in the Chalmers gasifier operated with ash-coated olivine [8], and it is in line with the net transport of S and $\mathrm{K}$ from the combustor to the gasifier in DFB units, as reported previously [8, 29]. Nevertheless, one cannot dismiss the possibility that there exist additional K-release routes that do not involve Scompounds, e.g., the release of K from the K-Ca-Si and K-Ca-P systems [36], which are also compatible with the elemental analysis of the ash layer.

The present investigation shows that the outermost ash-layer in olivine can act as a reservoir of releasable catalytic K. As shown in Fig.3, different levels of catalytic activity are possible 
depending on the availability of releasable $\mathrm{K}$ in the ash-layer. The results suggest that the catalytic activity and the release rate of $\mathrm{K}$ by the ash layer are linked. In the present investigation, the gas-phase concentration of $\mathrm{K}$ species and the release rate of $\mathrm{K}$ were not quantified. However, there is experimental evidence to suggest their relevance to bed materialcatalyzed gasification. Therefore, a thorough understanding of the catalytic activity of ashcoated olivine towards char gasification will require the quantification of the release rate of catalytic K, as well as the identification of the parameters that govern the release rate.

\section{Conclusions}

The catalytic activity of olivine towards the steam gasification reaction has been investigated in this work. It is shown that ash-coated olivine activated by the in-bed addition of $\mathrm{K}\left(\mathrm{K}_{2} \mathrm{CO}_{3}\right)$ and S catalyzes the steam gasification of char. This catalytic activity can be attributed to the transfer of $\mathrm{K}$, presumably as gaseous $\mathrm{KOH}$, from the ash layer on olivine to the char matrix under steam gasification conditions.

This work emphasizes the role of the ash-layer on the olivine particles as a carrier of K. Sulfur contributes to the transport of $\mathrm{K}$ in a releasable form from the outermost ash-layer. Taken together, these findings provide insights into the catalytic effect of ash-coated materials for char gasification in fluidized bed reactors.

\section{Acknowledgments}

This work was supported financially by the Swedish Gasification Center (SFC) and the BioProGReSs Project, which has received funding from the European Union's Seventh Framework Programme (FP7 grant agreement 321477).

\section{References}

1. Di Blasi, C., Combustion and gasification rates of lignocellulosic chars. Progress in Energy and Combustion Science, 2009. 35(2): p. 121-140. 
2. Nzihou, A., B. Stanmore, and P. Sharrock, A review of catalysts for the gasification of biomass char, with some reference to coal. Energy, 2013. 58(0): p. 305-317.

3. Devi, L., K.J. Ptasinski, and F.J.J.G. Janssen, A review of the primary measures for tar elimination in biomass gasification processes. Biomass and Bioenergy, 2003. 24(2): p. 125140.

4. Anis, S. and Z.A. Zainal, Tar reduction in biomass producer gas via mechanical, catalytic and thermal methods: A review. Renewable and Sustainable Energy Reviews, 2011. 15(5): p. 2355-2377.

5. Keller, M., et al., Gasification inhibition in chemical-looping combustion with solid fuels. Combustion and Flame, 2011. 158(3): p. 393-400.

6. Berdugo Vilches, T., et al., Comparing Active Bed Materials in a Dual Fluidized Bed Biomass Gasifier: Olivine, Bauxite, Quartz-Sand, and IImenite. Energy \& Fuels, 2016. 30(6): p. 48484857.

7. Keller, M., H. Leion, and T. Mattisson, Mechanisms of Solid Fuel Conversion by ChemicalLooping Combustion (CLC) using Manganese Ore: Catalytic Gasification by Potassium Compounds. Energy Technology, 2013. 1(4): p. 273-282.

8. Marinkovic, J., et al., Characteristics of olivine as a bed material in an indirect biomass gasifier. Chemical Engineering Journal, 2015. 279: p. 555-566.

9. Kirnbauer, F., et al., The positive effects of bed material coating on tar reduction in a dual fluidized bed gasifier. Fuel, 2012. 95: p. 553-562.

10. Kuba, M., et al., Influence of bed material coatings on the water-gas-shift reaction and steam reforming of toluene as tar model compound of biomass gasification. Biomass and Bioenergy, 2016. 89: p. 40-49.

11. Kern, S., C. Pfeifer, and H. Hofbauer, Reactivity tests of the water-gas shift reaction on fresh and used fluidized bed materials from industrial DFB biomass gasifiers. Biomass and Bioenergy, 2013. 55: p. 227-233.

12. Kudo, S., et al., Examination of Kinetics of Non-catalytic Steam Gasification of Biomass/Lignite Chars and Its Relationship with the Variation of the Pore Structure. Energy \& Fuels, 2014. 28(9): p. 5902-5908.

13. Mermoud, F., et al., Influence of the pyrolysis heating rate on the steam gasification rate of large wood char particles. Fuel, 2006. 85(10-11): p. 1473-1482.

14. Cetin, E., et al., Influence of pyrolysis conditions on the structure and gasification reactivity of biomass chars. Fuel, 2004. 83(16): p. 2139-2150.

15. Wang, L., et al., Release of Potassium During Devolatilization of Spruce Bark. Energy Procedia, 2017. 105: p. 1295-1301.

16. Lundberg, L., et al., Influence of surrounding conditions and fuel size on the gasification rate of biomass char in a fluidized bed. Fuel Processing Technology, 2016. 144: p. 323-333.

17. Tchoffor, P.A., K.O. Davidsson, and H. Thunman, Transformation and Release of Potassium, Chlorine, and Sulfur from Wheat Straw under Conditions Relevant to Dual Fluidized Bed Gasification. Energy \& Fuels, 2013. 27(12): p. 7510-7520.

18. Umeki, K., et al., A model of biomass char gasification describing the change in catalytic activity of ash. Chemical Engineering Journal, 2012. 207-208: p. 616-624.

19. Lundberg, L., et al., Determination of Kinetic Parameters for the Gasification of Biomass Char Using a Bubbling Fluidized Bed Reactor, in 22nd International Conference on Fluidized Bed Conversion. 2015: Turku, Finland.

20. Ahmed, I.I. and A.K. Gupta, Kinetics of woodchips char gasification with steam and carbon dioxide. Applied Energy, 2011. 88(5): p. 1613-1619.

21. Veraa, M.J. and A.T. Bell, Effect of alkali metal catalysts on gasification of coal char. Fuel, 1978. 57(4): p. 194-200.

22. Wigmans, T., R. Elfring, and J.A. Moulijn, On the mechanism of the potassium carbonate catalysed gasification of activated carbon: the influence of the catalyst concentration on the reactivity and selectivity at low steam pressures. Carbon, 1983. 21(1): p. 1-12. 
23. Liu, Z.-I. and H.-h. Zhu, Steam gasification of coal char using alkali and alkaline-earth metal catalysts. Fuel, 1986. 65(10): p. 1334-1338.

24. Zhang, Y., et al., Proposal of a semi-empirical kinetic model to reconcile with gasification reactivity profiles of biomass chars. Fuel, 2008. 87(4-5): p. 475-481.

25. Yip, K., et al., Effect of alkali and alkaline earth metallic species on biochar reactivity and syngas compositions during steam gasification. Energy \& Fuels, 2009. 24(1): p. 173-181.

26. Lobo, L.S., Intrinsic kinetics in carbon gasification: Understanding linearity, "nanoworms" and alloy catalysts. Applied Catalysis B: Environmental, 2014. 148-149: p. 136-143.

27. Kirnbauer, F. and H. Hofbauer, Investigations on Bed Material Changes in a Dual Fluidized Bed Steam Gasification Plant in Güssing, Austria. Energy \& Fuels, 2011. 25(8): p. 3793-3798.

28. Kuba, M., et al., Mechanism of Layer Formation on Olivine Bed Particles in Industrial-Scale Dual Fluid Bed Gasification of Wood. Energy \& Fuels, 2016. 30(9): p. 7410-7418.

29. Kirnbauer, F., et al., Behavior of inorganic matter in a dual fluidized steam gasification plant. Energy \& Fuels, 2013. 27(6): p. 3316-3331.

30. Johansson, L., et al., Particle emissions from biomass combustion in small combustors. Biomass and bioenergy, 2003. 25(4): p. 435-446.

31. Hüttinger, K.J. and R. Minges, The influence of the catalyst precursor anion in catalysis of water vapour gasification of carbon by potassium: 2 . Catalytic activity by activation and deactivation reactions. Fuel, 1986. 65(8): p. 1122-1128.

32. Wang, J., et al., Enhanced catalysis of K2СO3 for steam gasification of coal char by using $\mathrm{Ca}(\mathrm{OH}) 2$ in char preparation. Fuel, 2010. 89(2): p. 310-317.

33. Arnold, R.A., et al., Interaction of Potassium and Calcium in the Catalytic Gasification of Biosolids and Switchgrass. Energy \& Fuels, 2017.

34. Hüttinger, K.J. and R. Minges, Influence of the catalyst precursor anion in catalysis of water vapour gasification of carbon by potassium. Fuel, 1986. 65(8): p. 1112-1121.

35. Adler, J. and K.J. Hüttinger, Mixtures of potassium sulphate and iron sulphate as catalysts for water vapour gasification of carbon. 1. Kinetic studies. Fuel, 1984. 63(10): p. 1393-1396.

36. Novaković, A., et al., Release of Potassium from the Systems $K$-Ca-Si and K-Ca-P. Energy \& Fuels, 2009. 23(7): p. 3423-3428.

37. McKee, D.W., Mechanisms of the alkali metal catalysed gasification of carbon. Fuel, 1983. 62(2): p. 170-175.

38. Larsson, A., et al., Evaluation of Performance of Industrial-Scale Dual Fluidized Bed Gasifiers Using the Chalmers 2-4-MWth Gasifier. Energy \& Fuels, 2013. 27(11). 